\title{
How to lead educational change
}

\author{
Dennis Shirley ${ }^{1}$
}

Published online: 8 August 2016

(c) Springer Science+Business Media Dordrecht 2016

From some perspectives, educational change frequently is an irrational process. Governments concoct plans to privatize school systems based on ideology rather than consulting populations or the profession (Abrams 2016; Adamson et al. 2016). Even when change is research-based, resistance sets in amongst teachers in schools with low social capital and their opposition thwarts even the best-laid plans (Bryk and Schneider 2002; Payne 2008). The public becomes infatuated with fads like 1:1 computers in schools, and evidence eventually surfaces that student learning has suffered as a consequence (Islam and Grönlund 2016; OECD 2015).

For others, however, change is more promising. Governments study research and design curriculum to improve learning (Fullan and Quinn 2016; Ng 2016; Sahlberg 2015). Based on careful study of evidence, reforms are tested out that draw upon educators' professionalism and drive up achievement (Lubienski and Lubienski 2013). New digital tools serve to improve learning results not just in Europe or North America, but also in Latin America and Asia (Vega 2015). While setbacks occur, the larger arc of history shows that students learn more and even live longer as a result of their years of formal education (Krueger et al. 2015).

Still other perspectives occupy an intermediate zone. Change can be irrational but its unpredictability isn't necessarily problematic because it can generate hitherto unanticipated benefits if there is space for local actors to modify and adjust government policies (Shirley and MacDonald 2016; Zhao 2009). Universal Design for Learning tools can be implemented for students with dyslexia that uplift learning for everyone (Hargreaves and Braun 2012). In these cases patience is needed to see

Dennis Shirley

Shirleyd@bc.edu

1 Lynch School of Education, Boston College, 140 Commonwealth Avenue, Campion Hall, Chestnut Hill, MA 02467-3813, USA 
reforms through and research methodologies have to be open-ended and flexible enough to capture the subtle and labyrinthine nature of change.

While there are different emphases in the five articles in this issue of The Journal of Educational Change, in general they all support a positive view of change. The first of these, by Charlene Tan, explores "Teacher Agency and School-based Curriculum in China's Non-Elite Schools." According to Tan, in 2001 China adopted School-Based Curriculum Development (SBCD) from Australia and the United Kingdom. This did not, however, entail a slavish imitation of western approaches to education. On the contrary: Chinese educators in non-elite schools used SBCD to recover and embed traditional knowledge systems-Confucianism in some schools, and indigenous ethnic cultures in others-into the curriculum. In this article, benevolent ministerial leadership, encouraging teachers to develop their skills as curriculum makers, led to a rich and locally responsive intervention in education that enabled students to acquire a deeper appreciation of their indigenous cultures than they would have attained in more competitive, western-oriented elite schools.

A similar approach to change is described by Arnd-Michael Nohl and R. Nazli Somel in their article entitled "Curricular Change in Turkey: Time, Sequentiality, and Differential Power of Actors in Establishing a New Knowledge Path." In 2002, the Ministry of Education in Turkey began the process of overhauling a longoutmoded behaviorist approach to the primary school curriculum. Using path theory as an approach to the study of curriculum reform, the authors show how policy evolved through four separate stages. The first of these, "bounded openness and contingency," pitted the increasingly influential theories of multiple intelligences and constructivism against the older behavioral approach. As Turkey was at the time endeavoring to establish its legitimacy as an open market to the European Community, the compelling influence of international "isomorphism" played a powerful role in shifting the discourse towards the new curriculum.

This initial sense of momentum, somewhat fragile at the time, then gathered speed through a series of "small events and a critical juncture" in which ministerial officials worked with higher education faculty, curriculum experts, and educators, to begin the process of curriculum development. In the second phase, generous funding from the European Community supported this stage of the project. This funding gave the project autonomy from an older guard of educators within the Ministry and the schools who were skeptical or outright opposed to its aspirations. This in turn led to a third phase of "increasing returns" in which trial products from the curriculum development project were piloted in schools and began to win acceptance from teachers.

Intriguingly, at this stage of the process an opponent of the constructivist and multiple intelligence approach to curriculum was placed in charge of the relevant unit at the Ministry. However, by this point a fourth phase, described by Nohl and Somel as "lock-in," had occurred. To reverse the curriculum at this time would have reflected ignorance of research on how students actually learn and would have sent a message of unreliability in terms of the government's capacity to use funding wisely to the European Community. In practice this meant that the curriculum reform process had become irreversible. As a consequence, the Turkish primary 
education curriculum reform was completed-albeit rather ironically-by a previously outspoken critic of the reforms.

For students of the learning sciences, the implementation of Turkish curriculum reforms represents success at bringing a more sophisticated view of how students acquire and elaborate knowledge than behaviorism can provide. To this extent, the Turkish reforms represent genuine progress, in spite of serious political obstacles. A significant finding here is that "those individuals who can steer the early, decisive events become the most powerful." If one wants to lead change, the key finding is that catalyzing change at an early stage is pivotal. At a certain point it becomes practically impossible to reverse change without undermining the legitimacy of a government, especially when that government has received external funding from donors with the political clout of the European Community.

The articles by Tan on China and by Nohl and Somel on Turkey thus lay out some of the markers of a positive and rational approach to educational change that acknowledges but does not overstate potential impediments to implementation. Lesson One: Study international research and policy trends. Lesson Two: adjust them to your home context. Lesson Three: Anticipate complexity but don't be paralyzed by it. Lesson Four: Create space for autonomous local leadership that is independent of government, but also not hostile to it.

If change is so straightforward, however, why does it so often stumble in practice? Part of the answer can be found in this issue's article by Solvor Mjølberg Lauritzen, entitled "Educational Change Following Conflict: Challenges Related to the Implementation of a Peace Curriculum in Kenya." Lauritzen describes conjoined efforts of international agencies such as UNESCO and UNICEF to work with the Kenyan Ministry of Education in implementing peace education curricula in Kenya after that country's ethnic conflicts in 2007-2008. While one might assume that there would be universal recognition of the need for curricula to help students to resolve conflicts peacefully, in reality the problems with this approach were multi-layered.

First, there was the problem that those regions most afflicted by the ethnic conflict felt least prepared, in school and society, to discuss it. Second, there was discord by the Kenyan Ministry of Education and transnational agencies such as UNICEF and UNESCO based upon their understandings of peace education-such as whether it should be "additive" to the existing curriculum or "integrative" with it. Third, the elective manner in which the curriculum was designed, without any real accountability for student learning of the curriculum, made it easy to be sidelined or omitted altogether.

The Kenyan case illustrates the complexity of leading change, especially in postconflict societies. In spite of the difficulties with implementing the curriculum, however, several positive outcomes should be noted. First, according to one UNICEF official, the curriculum contributed to a societal process of healing and cross-cultural reconciliation when it was indeed implemented. Second, the curriculum was most successfully implemented in schools with urban multiethnic populations; given the realities of on-going urbanization, such schools will have a major impact on the future of education in Kenya. Third, when school leaders actively endorsed peace education, they were able to rally their staffs to make sure 
that the curriculum was indeed taught. These findings indicate that when the proper conditions are in place, social harmony can be enhanced with education playing an important role in conflict resolution.

Similar themes are struck in the article by N. Yehya Chaar, V. Khamis, and R. Karami Akkary on "Teachers' Concerns Towards Change in Lebanese Private Schools and Their Relationship to Gender, Experience, and Type of Change." As was the case in Kenya, Lebanon has experienced major social upheavals in recent decades, including the arrival of more than 1 million Syrian refugees since 2011, who now make up more than $20 \%$ of that country's population. In situations of social turbulence, apparently neutral and technical tasks related to school accreditation can be of great concern to teachers. This was especially evident given teachers' untenured job statuses, the intensification of their workloads, and ambiguity about the nature of their collaboration while pursuing accreditation. The authors call for school leaders to attend to "the human side of school change" as teachers' concerns persisted even after the accreditation process was complete.

That unanticipated complexities of change need not be negative but can instead lead to felicitous outcomes is described in the final paper of this issue by Azilawati Jamaludin and David Hung. Here a curricular innovation related to "Digital Learning Trails" in Singapore sparked a whirlwind of self-initiated or "rhizomatic" transformations that scaled up learning in 11 participating schools. Simply because change cannot be rationally predicted and implemented in a linear fashion does not mean it should not be initiated with creativity and brio and then spread about in positive ways, according to the authors.

Taken together, the 5 articles in this volume of The Journal of Educational Change illustrate that even though change can be difficult, when carefully planned and inclusive of a diversity of perspectives, success can be attained in the most heterogeneous of circumstances. Change leaders in China, Turkey, Kenya, Lebanon, and Singapore have shown that the profession has the capacity and the will to lead change. We can do so in humanistic and uplifting ways, provided we have the patience and the fortitude to bring all of our educational constituents together in ways that promote a better future for our students.

\section{References}

Abrams, S. E. (2016). Education and the commercial mindset. Cambridge: Harvard University Press.

Adamson, F., Åstrand, B., \& Hammond, Darling. (2016). Global education reform: How privatization and public investment influence education outcomes. New York: Routledge.

Bryk, A. S., \& Schneider, B. (2002). Trust in schools: A core resource for improvement. New York: Russell Sage.

Fullan, M., \& Quinn, J. (2016). Coherence: The right drivers for change in schools, districts, and systems. Thousand Oaks, CA: Corwin.

Hargreaves, A., \& Braun, H. (2012). Essential for some, good for all: A research report of the development, design, and impact of Ontario's "Essential for some, good for all” initiative. Council of Directors of Education: Ottawa.

Islam, M. S., \& Grönlund, А. (2016). An international literature review of 1:1 computing in schools. Journal of Educational Change, 17(2), 191-222. 
Krueger, P. M., Tran, M. K., Hummer, R. A., \& Chang, V. W. (2015). Mortality attributable to low levels of education in the United States. PLoS One, 10(7), e0131809. doi:10.1371/journal.pone.0131809.

Lubienski, C., \& Lubienski, S. (2013). The public school advantage: Why public schools outperform private schools. Chicago: University of Chicago Press.

$\mathrm{Ng}$, P. T. (2016). Lessons from education reform in Singapore: Drawing strength from paradoxes. New York: Routledge.

OECD. (2015). Students, computers, and learning: Making the connection. Paris: Author.

Payne, C. M. (2008). So much reform, so little change: The persistence of failure in urban schools. Cambridge: Harvard Education Press.

Sahlberg, P. (2015). Finnish lessons 2.0.: What can the world learn from education change in Finland?. New York: Teachers.

Shirley, D., \& MacDonald, E. (2016). The mindful teacher (2nd ed.). New York: Teachers Collect Press.

Vega, V. (2015). Technology integration research review: Evidence-based programs by subject. Edutopia: What Works in Education. http://www.edutopia.org/technology-integration-researchevidence-based-programs. Accessed 15 July 2016.

Zhao, Y. (2009). Catching up or leading the way: American education in the age of globalization. Alexandria: ASCD. 